\title{
ENTREVISTA COM LUIGI FERRAJOLI
}

A Revista DESC teve a honra de conversar com o maestro Luigi Ferrajoli, um dos filósofos do direito mais importantes e lidos do mundo, com uma longa e conhecida história na defesa dos direitos fundamentais, seja como professor universitário na Itália (Roma, Camerino) seja como juiz nos anos sessenta e setenta, quando participou da fundação de uma associação de jovens juízes, "Magistratura Democratica", em defesa de garantias fundamentais no processo, e em particular no processo penal. Ferrajoli é autor de numerosas obras sobre diversos temas, entre os quais direito e lógica, análise da linguagem e filosofia da ciência, e foi o principal discípulo de Norberto Bobbio até se consolidar como um filósofo eminente do "Garantismo", com a difusão de sua obra mais impactante no Brasil e em toda a América Latina, o clássico “Direito e Razão" de 1989.

Por seus méritos e fama, recebeu o título de "doctor honoris causa" em dezenas de universidades em todo o mundo; seu livro mais recente é "Manifesto pela Igualdade" de 2018, ainda não publicado no Brasil (Manifesto per l'uguaglianza).

A possibilidade de questionar o Maestro italiano sobre os tópicos desta entrevista é uma oportunidade preciosa para ouvir seus pensamentos atuais e, para a Revista, é motivo de orgulho poder oferecer aos leitores as reflexões de Luigi Ferrajoli. A ele devemos não apenas a construção mais completa da teoria do garantismo, mas também a teoria mais rica e articulada da democracia constitucional, tema que talvez o Brasil de hoje, mais do que ninguém, precise ouvir.

Dividimos o texto em blocos temáticos conforme a ênfase dada por juristas e docentes participantes, aos quais o Comitê Editorial da Revista DESC agradece com especial atenção, dada a riqueza que proporcionaram com suas perguntas, gerando uma entrevista extraordinária. É o que esperamos oferecer aos(às) leitores(as) nas linhas que seguem. 


\section{LUIGI FERRAJOLI - ENTREVISTA \\ $1^{\text {a }}$ PARTE - GARANTISMO E PROCESSO PENAL}

\section{Pergunta de EDUARDO JOSÉ DA FONSECA COSTA.}

Juiz federal no Brasil. Doutor pela Pontifícia Universidade Católica de São Paulo. Ex-Presidente da Associação Brasileira de Direito Processual (2016-2019). Diretor da Revista Brasileira de Direito Processual.

Pergunta 1. Autores como Juan Montero Aroca (Espanha), Franco Cipriani (Itália) e Alvarado Velloso (Argentina) defendem o processo - civil e penal - como garantia de liberdade a serviço do jurisdicionado, não como método instrumental a serviço da jurisdição. Quais as semelhanças e dessemelhanças entre o seu garantismo e o deles?

Luigi Ferrajoli (L.F.): De acordo com o modelo garantista, o processo judicial - civil, penal, mas também administrativo e constitucional - é um procedimento destinado a investigar a "verdade", obviamente relativa e aproximada, em relação a uma violação do direito: um crime, um ilícito civil ou ilícitos de outro tipo, ou ainda um ato inválido, seja legislativo, administrativo ou negocial. As garantias processuais, portanto, são - ou melhor, deveriam ser - a tradução jurídica de regras epistemológicas elementares. São garantias de verdade, bem como de imunidade à arbitrariedade.

\section{Perguntas de FLÁvio BOECHAT ALBERNAZ.}

Promotor de Justiça, membro do Ministério Público do Estado de São Paulo; Promotor de Justiça Criminal em São José dos Campos; Mestre em Direito Penal pela PUC-SP.

Preâmbulo: Na Itália e no Brasil, o Garantismo vem sendo identificado com uma série de medidas de proteção a criminosos, por opor severos obstáculos à aplicação da lei penal e à efetiva e célere punição de crimes. Na prática forense e política, sua utilização tem sido direcionada à proteção do criminoso e não da vítima do crime ou da sociedade no caso de crimes contra interesses difusos, e tem sido feita de maneira seletiva, aplicada pelos tribunais e pelo Parlamento sobretudo para criminosos especiais, detentores do poder político e econômico. Por exemplo: na Itália, em julho de 1994, em meio às investigações feitas pelo pool de promotores da Mani Pulite, o Governo apresentou um Decreto alterando sensivelmente as regras sobre a prisão cautelar, vedando a sua decretação em crimes financeiros, de corrupção e outros dos quais eram acusados precisamente os envolvidos no megaesquema de corrupção conhecido como Tangentopoli. Na prática, uma pessoa que roubava uma pequena quantia em uma farmácia poderia ser alvo de prisão cautelar, enquanto outra que houvesse desviado trilhões (a moeda vigente na Itália à época era a lira) dos cofres do Estado ou das empresas teria garantida a liberdade. No Brasil, sobretudo nos tribunais superiores, em que alguns juízes têm atuado sob forte conflito de interesses (há magistrados das altas cortes ligados a "imputati eccellenti” por laços políticos e de amizade), o garantismo vem sendo seletivamente invocado como pretexto para justificar a proibição de prisão cautelar de 
acusados/investigados especiais ou para assegurar o excessivo alongamento dos processos, com vistas à prescrição e à impunidade. Feita essa breve introdução, pergunta-se:

\section{Pergunta 2. Essa é uma percepção correta? Se não é, onde estaria o erro?}

L.F.: Esta é uma percepção completamente errada: as garantias penais e processuais servem para proteger os inocentes e não os criminosos. Portanto é infundado qualquer apelo ao garantismo para sustentar a impunidade de crimes dos poderosos. "Garantias" e "garantismo", por outro lado, são expressões cujo significado vai muito além do direito penal. As garantias são as obrigações ou proibições correspondentes àquelas expectativas positivas ou negativas que são os direitos subjetivos. Em particular, são as técnicas de proteção de todos os direitos fundamentais, isto é, as proibições (ou limites) e as obrigações (ou restrições) impostas para suas garantias. Falaremos, portanto, de garantismo liberal e especificamente penal para designar os limites do arbítrio punitivo, seja o legislativo, o judicial ou policialesco, em garantia dos direitos de liberdade; de garantismo social para designar as obrigações de prestação correspondentes aos direitos sociais; de garantismo civil para designar os limites e restrições impostos aos poderes econômicos privados - em questões de trabalho, meio ambiente, segurança e afins - em garantia dos direitos de quem possa ser prejudicado por seu exercício desregulado; de garantias supranacionais e tendencialmente globais para designar as garantias quase totalmente ausentes relacionadas aos direitos fundamentais estabelecidos pelas incontáveis cartas e convenções internacionais até agora substancialmente inefetivas; de garantismo dos bens públicos ou fundamentais contra sua lesão em prejuízo dos direitos de todos.

Nesse sentido, o garantismo é a outra face - a face da efetividade - do constitucionalismo. É um conjunto de limites e obrigações impostas a qualquer poder, seja ele público ou privado, político ou judicial, estatal ou supraestatal, em garantia das diferentes classes de direitos subjetivos e, em particular, dos direitos fundamentais: dos direitos políticos, dos direitos civis, dos direitos de liberdade e dos direitos sociais. Portanto não é um obstáculo à aplicação do direito penal, mas ao contrário uma garantia da sua correção e mesmo da sua eficácia como instrumento de proteção das vítimas e da sociedade. A efetividade do direito penal, de fato, não vem de condenações sumárias de possíveis inocentes, mas de uma correta e efetiva apuração das responsabilidades penais, somente possível precisamente pelo respeito às garantias penais e processuais.

\section{Pergunta 3. Qual avaliação o senhor faz sobre os impactos práticos do modelo} garantista na vida da sociedade e no dia a dia das pessoas?

L.F.: O garantismo, infelizmente, não é popular. Especialmente em questões criminais, a opinião pública, devido a campanhas políticas em matéria de segurança política, tende a ser punitivista. As garantias não fazem parte da cultura de massa ou mesmo do senso comum. Os acusados, de acordo com a opinião corrente, não são presumidos inocentes, mas culpados. $\mathrm{O}$ 
garantismo não faz parte do senso comum, muito menos da subcultura de populistas que precisam, infelizmente, avançar imediatamente sobre bodes expiatórios. Em poucas palavras, é impopular, e isso é suficiente para o populismo político rejeitá-lo como um luxo das almas belas. Naturalmente, nos deparamos aqui com um paradoxo. O garantismo não é apenas um sistema de limites e obrigações ao poder punitivo, seja legislativo ou judicial, em garantia da liberdade de todos contra a punição excessiva ou arbitrária. É antes de tudo um sistema de regras racionais que garantem, o máximo possível, a busca plausível da "verdade processual” e, portanto, a punição dos verdadeiros culpados. Mas é justamente essa racionalidade que não é aceita nem compreendida por uma parte da opinião pública, deseducada pela mídia, que ao contrário aspira à justiça sumária, tendendo ao linchamento dos suspeitos. E isso também é suficiente para o populismo representar tais concepções e consequentemente os anseios de vingança.

O populismo penal é, em suma, funcional para o populismo político. Seu paradigma - o direito penal do inimigo - está em perfeita sintonia com a tendência do populismo político a se definir com base em inimigos. Todos os populismos precisam se legitimar através de um inimigo ou, melhor ainda, de mais inimigos: inimigos internos que conspiram e inimigos externos como a União Europeia ou a ONU; inimigos no alto, representados por elites, e inimigos abaixo, representados por migrantes e sujeitos desviantes; inimigos identificados com governos anteriores e inimigos que constituem as oposições. E é claro que a autoidentificação de maiorias populistas com o povo soberano, o racismo, o medo da criminalidade de rua, a intolerância ao dissenso, o desconforto com o pluralismo político ou institucional e o vitimismo permanente são os ingredientes dessa lógica do inimigo. $\mathrm{O}$ impacto prático do garantismo na sociedade está, portanto, ligado à crítica a essas subculturas e seus enganos e, por isso, ao crescimento do sentido cívico no nível das massas, que só pode provir de uma batalha cultural em apoio aos valores constitucionais, dos direitos fundamentais à dignidade paritária das pessoas.

\section{Pergunta 4. Para o garantismo, qual é a função da pena e do direito penal na sociedade?}

L.F.: O papel das penas e do direito penal, segundo a teoria garantista, consiste na prevenção e, por isso, na minimização da violência e da arbitrariedade na sociedade: não só da violência e arbítrio dos membros da comunidade, ou seja, os crimes, mas também da violência e do arbítrio de instituições punitivas, isto é, penalidades arbitrárias ou excessivas. Não esqueçamos a tese de Montesquieu de que não apenas a liberdade, mas também a segurança dos cidadãos é ameaçada, acima de tudo, por penas e condenações arbitrárias. 


\section{Perguntas de GUSTAVO OCTAVIANO DINIZ JUNQUEIRA.}

Especialista em direito penal pela Universidade de Salamanca; mestre e doutor em direito penal pela PUC-SP; pós-doutorado pela universidade de Coimbra; professor de direito penal na graduação e no pós-graduação lato e stricto sensu da faculdade de direito da PUC-SP; professor do curso Damásio; defensor público no estado de São Paulo, foi diretor da Escola da Defensoria Pública por 3 mandatos.

Preâmbulo: O discurso Garantista repercute no Brasil há décadas. O pensamento foi reverenciado e se tornou um importante instrumento persuasivo no debate jurídico. No entanto, a repetição descuidada da expressão "Garantismo" foi tão frequente que aos poucos pode ter se distanciado de seu significado original. Hoje é muito importante no Brasil uma corrente de pensamento, capitaneada por membros do Ministério Público e da Magistratura, autodenominada "Garantismo Penal Integral”, que afirma partir do pensamento de Luigi Ferrajoli para fixar como premissa que não deve ser dado foco apenas para as garantias individuais perante o poder punitivo estatal, sendo necessário "garantir" o interesse da coletividade perante o indivíduo criminoso. A conclusão da corrente de pensamento "Integral” é que seria possível e recomendável o sacrifício de direitos e garantias individuais (como liberdade, devido processo legal, ampla defesa, legalidade penal ou vedação de incriminação sem conduta ou culpabilidade) em prol da tutela penal dos direitos coletivos como "segurança pública", "saúde pública" e mesmo "regularidade da Administração Pública". Para a autodenominada corrente "integral”, a flexibilização não seria um limite de eficácia do garantismo diante de demandas punitivas da sociedade, mas uma consequência do próprio garantismo.

Pergunta 5. Questiona-se: Tendo como premissa a máxima efetividade do garantismo penal, deve ser aceita a flexibilização de garantias previstas nos tradicionais axiomas do garantismo em prol da tutela penal de interesses coletivos como "segurança pública", "saúde pública" ou "regularidade da administração pública"? É possível ter tal sacrifício como uma evolução natural e esperada do Garantismo na defesa dos interesses coletivos?

L.F.: Tenho afirmado que o "garantismo" não é apenas garantismo penal. O garantismo é um paradigma teórico válido para todos os direitos e todos os bens fundamentais. Mas isso não implica de modo algum as consequências que, de acordo com a sua pergunta, os expoentes do chamado "garantismo penal integral" gostariam de extrair. Não é compreensível quais vantagens a segurança pública, a saúde pública entre outras poderiam ter às custas de lesões a garantias processuais e criminais, enquanto, por outro lado, são absolutamente evidentes as violações aos direitos e à segurança dos cidadãos que resultariam de tais lesões. 


\section{Perguntas de JOÃo PAULO MARTINELLI.}

Professor no cursos de graduação e pós-graduação no Instituto de Direito Público de São Paulo (IDP/SP) e na Universidade Federal Fluminense (RJ), Brasil. Pós-doutor em Direitos Humanos pela Universidade de Coimbra/Portugal. Mestre e Doutor em Direito Penal pela Faculdade de Direito da Universidade de São Paulo/Brasil. Foi membro da Comissão de Jovens Penalistas da Associação Internacional de Direito Penal (AIDP). Foi pesquisador na Universidade de Munique (Alemanha) e na Universidade da California (UC Davis, EUA). Cursou pós-graduação em Direito Penal (teoria do delito) na Universidade de Salamanca (Espanha). Especializado em Direito Penal Internacional pelo International Institute of Higher Studies in Criminal Sciences (ISISC). Coordenador de convênios do Instituto Brasileiro de Ciências Criminais (IBCCRIM/Brasil). Membro da Comissão de Direito Penal Econômico da OAB/SP-Brasil.

Pergunta 6. No Brasil, é muito comum o juiz criminal interrogar testemunhas e fazer perguntas minuciosas, detalhistas, como se quisesse produzir provas contra o réu. No sistema acusatório verdadeiro, o juiz pode interrogar testemunhas?

L.F.: No sistema acusatório, o juiz deve manter uma postura de total equidistância e imparcialidade. Não lhe é, portanto, permitido interrogar testemunhas, uma vez que isso compete às partes do processo. Muito menos pode constituir provas contra o acusado. Provas e contraprovas vão surgindo no debate público e no contraditório, por iniciativa da acusação e da defesa.

Pergunta 7. A doutrina tradicional brasileira, e também a jurisprudência, defendem o princípio da verdade real, segundo o qual o juiz deve buscar a verdade dos fatos para formar sua convicção. Essa postura dá ao juiz um papel de protagonista, como se fosse parte do processo. Qual sua opinião sobre o denominado princípio da verdade real?

L.F.: A única verdade que legitima o processo é a verdade processual, adquirida mediante o rigoroso respeito de todas as garantias do devido processo. Eu não compartilho de maneira alguma com o assim chamado princípio da verdade material que, além das intenções, sempre corre o risco de se transformar em uma legitimação do arbítrio. Naturalmente, os juízes, por princípio, devem estar cientes da natureza probabilística da verdade real e do caráter discutível da verdade jurídica. A dúvida é a primeira regra da deontologia judicial.

Pergunta 8. Recentemente, uma desembargadora brasileira foi processada administrativamente por conceder a liberdade a presos que estavam em reclusão além do tempo previsto na decisão condenatória. $O$ principal argumento do tribunal foi a violação ao princípio da colegialidade, pois ela era integrante de uma câmara criminal. Existe realmente um princípio da colegialidade? Uma decisão que revoga uma prisão ilegal pode ser proferida monocraticamente por membro de tribunal?

L.F.: Não conheço o processo brasileiro, nem, portanto, a distribuição de competências determinada pelo "princípio de colegialidade" mencionado na pergunta. Se a juíza "processada administrativamente por conceder a liberdade a presos que estavam em reclusão além do tempo previsto na decisão condenatória" tivesse competência para emitir tal disposição, então seu ato não era apenas lícito, mas um dever, e o procedimento administrativo foi completamente infundado. 
Pergunta 9. Qual deve ser o papel da vítima no desenvolvimento do processo penal? A vítima pode atuar como assistente de acusação ou esse papel deve ser exclusivo do titular da ação penal?

L.F.: A vítima é titular apenas do direito de, no caso de uma condenação, pedir ressarcimento pelos danos sofridos. Quanto ao processo penal, a vítima está legitimamente interessada não na condenação qualquer que seja, mas na busca da verdade processual, isto é, em averiguar a responsabilidade dos verdadeiros culpados e, portanto, em respeitar as garantias processuais que, como tenho afirmado, são acima de tudo garantias da verdade.

\section{Perguntas de PASQUALE BRONZO.}

Professor Associado de direito processual penal na Sapienza Università di Roma.

Pergunta 10. Em sua ideia de reforma do sistema penal, está prevista uma redução de crimes, também por meio de uma descriminalização, entre outros, dos crimes que não têm um genuíno efeito de dissuasão, aqueles que proíbem "comportamentos que são cometidos de qualquer maneira, cujas penas têm o único efeito criar clandestinos" (Ferrajoli, L., Dei diritti e delle garanzie, Il Mulino, 2013, p. 26). Entre os crimes desse último tipo, o senhor menciona o crime de imigração irregular (artigo 10-bis do Decreto Legislativo de 25 de julho de 1998, n. 286) introduzido na Itália em 2009, que se mostrou sem qualquer efeito dissuasivo e capaz de apenas empurrar os migrantes ilegais para a clandestinidade, contribuindo para torná-los presas fáceis de organizações criminosas como a máfia. Um exemplo paradigmático de uso simbólico do direito penal: o estrangeiro que entra ilegalmente - o qual não pode ser presopor se tratar de uma contravenção é julgado meses ou anos depois (geralmente na sua ausência), condenado a uma multa que nunca é cobrada (enquanto o processo custa à comunidade, não só em termos de pessoal no judiciário, mas também porque o estrangeiro necessitado tem o direito de ser defendido pelo Estado). Essa incriminação - inútil em si mesma - foi introduzida apenas para manter a possibilidade 'tranquilizadora' de expulsão compulsória do clandestino (sem conceder condições para sua saída voluntária) que uma diretiva europeia de 2008 nos permite somente se a expulsão for uma sanção penal ou consequência de uma sentença criminal. Acontece que, se durante o processo ocorrer a expulsão pela via administrativa, o processo fica bloqueado, apesar de a pena prevista ser pecuniária, substituível pela expulsão sempre que possível. No entanto, esse tipo particular de expulsão penal é quase sempre impossível, pelas mesmas razões que a administrativa o é, levando à não aplicação da lei quase generalizada (na verdade, a maioria das decisões judiciais não a aplicam, sendo causa também de inaceitáveis divergências de julgamento). $O$ senhor acredita que o sistema penal "expansionista” do Brasil, que sempre foi propenso à legislação simbólica, 
hoje atormentado por problemas de imigração maciça como a oriunda da Venezuela, pode se inspirar no exemplo negativamente instrutivo de nosso crime de "clandestinidade"?

L.F.: O direito penal, segundo seu modelo garantista, não tem a função de declamar princípios políticos, mas apenas de prevenir danos injustos. As leis penais destinadas a permanecer ineficazes - como aquelas que penalizam o aborto ou a imigração ilegal ou o uso pessoal de drogas - para além daquilo que pensamos sobre sua ilegitimidade moral e política, são normas injustificadas simplesmente porque não são capazes de prevenir os fatos penalizados por elas. Além disso, elas sempre tendem a ser criminógenas, dado que seu principal efeito é tornar clandestinos os comportamentos que elas preveem e proíbem. Sua ineficácia, relatada em sua pergunta, é uma confirmação da inutilidade, ou pior, da nocividade de tais normas.

Pergunta 11. O Brasil vive atualmente um grave problema de superlotação nas prisões (quarta maior população carcerária do mundo). Em sua ideia de reforma da justiça na Itália, há uma forte redução do cárcere, a ser alcançada não apenas diminuindo a duração das penas, mas também introduzindo penas de detenção não prisionais para crimes de baixa gravidade, com conteúdo semelhante ao das atuais penas alternativas à prisão, mas aplicadas diretamente em sentença do juiz de cognição (Ferrajoli, L., Dei diritti e delle garanzie, Il Mulino, 2013, p. 28). Na Itália, estivemos muito próximos de aprovar uma reforma semelhante em 2014, por meio de um novo catálogo de sanções: prescrições, prisão domiciliar e, possivelmente, junto com esta última, prestação de serviços de utilidade pública à comunidade; com uma completa reconfiguração do trabalho "penal" que, nascido como punição e depois tornado um expediente para agravar a prisão e, portanto, um meio de dar significado a ela, voltaria a ser uma punição, mas fora e sem prisão. O senhor acha que esse modelo é viável mesmo em um sistema caracterizado por um verdadeiro e claro encarceramento em massa como o sistema brasileiro?

L.F.: A superlotação é, em si mesma, um tratamento contrário ao senso de humanidade que, como tal, é ilegítimo e não deve ser de modo algum permitido. Quanto ao encarceramento em massa, no Brasil como nos Estados Unidos, é sempre o sinal inequívoco do caráter discriminatório e classista do direito penal desses países. Tanto mais nesses países, por isso, seria necessário impor processos de descriminalização e de desencarceramento. Há anos venho propondo, por um lado, a redução da duração máxima das penas para 15 ou no máximo 20 anos e, por outro lado, a previsão de uma ampla gama de sanções penais alternativas à reclusão para todos os crimes não graves. Acrescento que uma verdadeira política anticrime, que realmente tenha foco na segurança, deveria ser, muito mais do que uma política criminal, uma política social, capaz de reduzir as causas econômicas e materiais da criminalidade de rua e de subsistência e, obviamente, mais difícil e trabalhosa que o simples agravamento demagógico das penas. 
Pergunta 12. O senhor é um dos primeiros e principais defensores do princípio da "reserva do código" como uma ferramenta para restaurar a certeza, a cognoscibilidade e a natureza sistemática a um direito penal que - sobretudo por causa de uma enorme produção normativa e da cada vez mais evidente "descodificação" - perdeu certeza, cognoscibilidade, coerência interna; tanto é assim que - como o senhor lembra (Ferrajoli, L., Crisi della legalità penale e giurisdizione. Una proposta: la riserva di codice, in Legalità e giurisdizione. Le garanzie penali tra incertezze del presente ed ipotesi del futuro, Padova, 2001, p. 27 ss) - um acórdão do Tribunal Constitucional de 1988 chegou a declarar que o princípio de que "a ignorância da lei não é escusável” não se aplica quando a ignorância é inevitável.

Na Itália, no ano passado, esse princípio foi implementado - embora com limites importantes - no decreto legislativo de 1 de março de 2018, n. 21, que introduziu (no código penal, isto é, numa lei ordinária) uma disposição segundo a qual "novas disposições que preveem crimes só podem ser introduzidas na lei se modificarem o código penal ou forem incluídas na legislação orgânica que regula a matéria". O senhor acredita que, na realidade atual, caracterizada - em nível global - por um direito penal cada vez mais "multinível" e por um uso cada vez mais frequente de tipos criminais como normas de "fechamento" em determinadas disciplinas setoriais, existem condições político-culturais para observar o princípio da "reserva do código" como originalmente concebido, ou pensa que é inevitável aceitar - de acordo com a definição do decreto - uma racionalização da produção legislativa que, sem eliminar o direito penal extra-codicem, exige que o legislador crie tantas leis orgânicas quanto possível?

L.F.: Tenho desenvolvido há várias décadas a proposta da reserva do código, que é uma reserva da lei penal reforçada e adequada para garantir ao direito penal cognoscibilidade mesmo antes da certeza. É uma proposta que se tornou ainda mais necessária e urgente diante da complexidade do sistema de fontes, e até mesmo, como você diz, num direito penal "multinível", o qual por sua vez deveria estar sujeito a uma reserva do mesmo tipo. Trata-se de uma garantia banal de racionalidade e de cognoscibilidade, que só pode ser combatida pela demagogia populista e que seria avessa ao uso conjuntural e propagandístico do direito penal. 


\section{LUIGI FERRAJOLI - ENTREVISTA 2a PARTE - GARANTISMO E CONSTITUZIONALISMO}

\section{Perguntas de ENZO BELLO.}

Doutor em direito (UERJ). Estágios de Pós-Doutorado em Direito (UNISINOS) e Serviço Social (UFRJ). Professor Adjunto da Faculdade de Direito da UFF e do Programa de Pós-Graduação em Direito Constitucional (PPGDC) da UFF. Editor-chefe da Revista Culturas Jurídicas (www.culturasjuridicas.uff.br).

Pergunta 13. O senhor tem conhecimento do chamado "novo constitucionalismo latino-americano", representado pelas Constituições de Venezuela (1999), Equador (2008) e Bolívia (2009)?

Luigi Ferrajoli (L.F.): Eu tenho um conhecimento um tanto sumário desses temas. Já falei várias vezes, a propósito dessas constituições e sobretudo a brasileira, do "constitucionalismo de terceira geração". Essas constituições são constituições longas, segundo o modelo da constituição portuguesa e, acima de tudo, introduziram novos direitos, como os direitos à água, ao acesso às comunicações e às tecnologias da informação, ao uso do gás e da eletricidade nas constituições de Equador e Bolívia. Mas me causam algumas perplexidades a categoria "direitos da natureza", que é obviamente uma figura metafórica, presente no artigo 71 da Constituição do Equador. Mais apropriada e eficaz teria sido a qualificação constitucional como bens públicos e estatais, subtraídos do mercado e da disponibilidade política, ou bens naturais como a água, o ar, os rios, os mares e em geral aqueles que Gaio descreveu como "res communes omnium".

Pergunta 14. Vinculado a isso, o senhor teve contato com a produção teórica latinoamericana sobre Direito Constitucional, Teoria do Direito e/ou Direitos Humanos? Caso positivo, identifica afinidades em relação à sua obra, produzida a partir do contexto europeu?

L.F.: Eu vejo afinidades em qualquer orientação teórica que vise fortalecer as garantias dos direitos humanos. Em particular, sublinhei várias vezes o valor de muitas novas garantias inventadas pelo constitucionalismo latinoamericano: desde os tribunais eleitorais e outras instituições eleitorais de garantia introduzidas no México até o ministério público de defesa introduzido na Argentina e em muitos outros países latinoamericanos; das obrigações orçamentárias que no Brasil se impõem à destinação de recursos para garantir os direitos à saúde e à instrução de cotas mínimas de gastos públicos com as funções de garantia desses direitos, ainda no Brasil, confiados ao Ministério Público, até a previsão, também no Brasil, de um Procurador junto ao Tribunal Constitucional competente, juntamente com outros sujeitos (partidos políticos, presidente, governadores e outros), para promover a ação de inconstitucionalidade.

Pergunta 15. Qual a sua avaliação sobre a relação entre os planos teóricos e práticos do neoconstitucionalismo / pós-positivismo jurídico e o neoliberalismo?

L.F.: Sou contra todas as orientações teóricas de tipo antijuspositivistas, sejam pós- 
positivistas ou apositivistas ou jusnaturalistas. Na minha opinião, há uma ligação instrumental, geralmente negligenciada, entre o positivismo jurídico, o garantismo e a democracia. $\mathrm{O}$ positivismo jurídico forma o pressuposto necessário do garantismo, que é a outra face do constitucionalismo e, portanto, da democracia constitucional. A positivação de regras formais e substantivas sobre a produção jurídica revelou-se de fato como a técnica que tornou possível a democratização tanto das formas como dos conteúdos do direito. E essa é uma tese descritiva, independente de nossas opções filosóficas ou políticas de tipo jusconstitucionalista, juspositivista ou jusnaturalista, ou ainda realista ou liberalista. Obviamente, nem o constitucionalismo nem o

positivismo jurídico implicam democracia e garantismo. É inegável, contudo, que a positivação das normas formais sobre as formas de produção jurídica, operadas com o primeiro positivismo jurídico do Estado legislativo de direito, permitiu estipular, como normas de direito positivo, as regras formais da democracia política, do sufrágio universal à representação política, da separação de poderes ao controle de constitucionalidade das leis. Por outro lado, a positivação das normas substantivas sobre os conteúdos da produção legislativa, realizada com o segundo positivismo jurídico do Estado constitucional de direito, possibilitou estipular as regras da democracia substancial como normas positivas de nível superior a todas as outras e, com isso, os limites e obrigações impostos às maiorias sob a forma de direitos fundamentais das pessoas por ela estabelecidos.

\section{Perguntas de PIERRE MOUSSERON.}

Professor de direito empresarial na Faculdade de Direito de Montpellier - França. Presidente do Instituto de Usos Mercantis (Institut des Usages - Montpellier -France. https://bibliotheque-des-usages.cde-montpellier.com/presentation-de-I-institutdes-usages).

Pergunta 16. A União Europeia tem adotado leis penais especiais no que diz respeito ao combate à lavagem de dinheiro. Além disso, a Corte de Justiça da União Europeia tem tomado decisões em matéria penal que reduzem alguns princípios bem estabelecidos, como o da personalidade das infrações penais (CJUE 5 de março de 2015, C-343-13). $O$ senhor concorda que a União Europeia esteja excedendo seus poderes com tais ações?

L.F.: O princípio de culpabilidade é um princípio garantista absolutamente básico. $\mathrm{O}$ enfraquecimento deste princípio deve ser criticado em si, e não porque a legislação penal deve permanecer fora das competências da União Europeia. Pelo contrário, sempre afirmei que o processo de integração da União exige, entre outras inovações institucionais - em primeiro lugar a forma política federal - a unificação jurídica de grande parte da legislação básica. A existência, na Europa, de 27 códigos civis, 27 códigos penais e tantos outros códigos de processo substancialmente semelhantes não faz sentido. A unificação legal, em particular da codificação penal, seria um fator seguro de integração, de crescimento da igualdade e, em conjunto, da eficácia do direito penal. 
Pergunta 17. No meu centro de estudos em Montpellier, há um interesse muito antigo e forte na validade dos usos como fonte de direitos, principalmente em relação às pessoas jurídicas e associações tradicionais de produtores e vendedores (vinho, por exemplo) diante das regras gerais da União Europeia. Na sua experiência na defesa de direitos e garantias individuais, como o senhor pensa atualmente sobre os direitos desses sujeitos jurídicos? Concentrando-nos em nosso tópico sobre "usos jurídicos", considerando que os regulamentos formais podem ser vistos como uma causa de aumento da burocracia, o senhor acha que regras informais como usos poderiam ser, pelo menos em algumas áreas, uma alternativa válida para um processo infinito de "formalização" legal de direitos individuais?

L.F.: Usos e costumes são certamente fontes informais de direito, que estão recuperando uma relevância que parecia ter cessado em um passado não muito distante. Contudo, continuo a pensar que a sua legitimidade é condicionada pela sua não oposição à lei. Tenho receio de que dificilmente possam se tornar "uma alternativa válida" à formalização legal dos direitos fundamentais.

\section{Perguntas de NATALIA GASPAR.}

Professora de direito econômico, direito penal empresarial e direitos humanos na Universidad Autonoma de Puebla BUAP/ México.

Pergunta 18. A chegada da esquerda ao poder no México em 2018 é vista como um passo de transformação para a democracia dentro do modelo neoconstitucionalista e garantista?

L.F.: Espero sinceramente que o novo Presidente mexicano consiga promover um crescimento democrático do México, por meio de uma maior garantia dos direitos sociais e, portanto, de uma redução da pobreza e das enormes desigualdades. Eu acrescento que um crescimento efetivo da democracia só pode ser impedido por tentações populistas, sempre tendendo a entrar em conflito com o paradigma garantista.

Pergunta 19. Pode o México e sua constituição de 1917 com mais de 600 reformas, além de reformas em matéria econômica em 2013 (telecomunicações, energia, concorrência financeira e econômica), estar em consonância com o neoconstitucionalismo?

L.F.: "Neoconstitucionalismo", na minha opinião, é uma expressão equivocada e por vezes enganosa. Prefiro falar do constitucionalismo tout court, ou constitucionalismo jurídico ou garantista, gerado pelas atuais constituições rígidas, em oposição ao constitucionalismo político, que, em vez disso, é uma doutrina política muito mais antiga, baseada no governo das leis em oposição ao governo dos homens. Quanto à antiga Constituição mexicana, o problema 
real, muito mais do que a sua reforma, é a implementação dos muitos direitos fundamentais por ela estabelecidos, começando pelos direitos sociais à saúde, à educação e à subsistência, por meio da introdução por via legislativa de garantias adequadas e funções e instituições de garantia adequadas.

\section{Perguntas de JOSÉ ANTONIO SIQUEIRA PONTES.}

Mestre e doutor em filosofia e teoria geral do direito pela Universidade de São Paulo (USP). Professor pesquisador das Faculdades de Campinas (FACAMP). Coordenador do grupo de pesquisas sobre fundamentos econômicos e sociológicos da integridade empresarial (compliance)/FACAMP.

Preâmbulo: Em suas obras sobre o constitucionalismo como manifestação do garantismo, ao menos desde a década de 2000, o senhor apresenta um senso de realidade sociológica ao apontar as crises dos sistemas de proteção de direitos e as necessárias transformações do direito local e global para superar as dificuldades. Destaco aqui a importância que o senhor dá à esfera pública, aos poderes de Estado enquanto opostos aos interesses privados de pessoas e corporações. Essa esfera pública é a base conceitual para a garantia efetiva de um conjunto de direitos de constituições e de tratados internacionais, como o acesso à renda mínima, à saúde e à educação gratuitas, ao meio ambiente sadio etc. Na análise penal, o senhor muitas vezes associa essas metas básicas de cidadania com as metas de direito penal mínimo, ou seja, redução da criminalidade de massa e do encarceramento crescente das classes pobres. Enfim, se compreendi bem, o senhor defende uma teia conceitual conectando a efetivação de direitos básicos a uma esfera pública forte apta a contrariar interesses privados, mediante a necessária ampliação de várias funções estatais nacionais e o fortalecimento dos organismos internacionais, rumo a uma nova forma de constitucionalismo global. Em paralelo, observamos que organismos internacionais como OCDE, FMI, Banco Mundial, IOSCO, Basel Committee, entre outros, revelam recentes mudanças de padrão dos "direitos" advindos do ambiente internacional, como condição de boa "governança privada". Essa ideia de governança aparece como uma manifestação de uma "nova ordem liberal", portanto regida em harmonia com os interesses empresariais privados tais como transparência, integridade e redução de riscos. Porém a lógica da governança se acopla cada vez mais à gestão dos Estados, por um lado, pela via da eficiência, da saúde fiscal, corte de custos e, por outro lado, pela via da delegação de poderes e funções públicas ao ambiente privado (autoconstitucionalização, autorregulação etc.), que é uma outra face do lema "privatização". Por outro lado, esse fenômeno global tem outra face interessante: esses mesmos organismos internacionais paragovernamentais (OCDE, FMI, Banco Mundial, IOSCO, Basel) parecem legislar em padrão considerado "soft law", ao definir diretrizes internacionais que são fonte complementar de leis dos Estados (leis penais, civis e administrativas) muitas delas mais vigentes que muitas leis nacionais na prática. Elas parecem fortalecer em alguma medida 
as possibilidades futuras de uma comunidade pública internacional e a ONU alinha cada vez mais suas agendas de direitos fundamentais e sustentabilidade (Agenda 2030) ao discurso da governança, transparência do combate à corrupção, ao terrorismo e à lavagem de capitais. As perguntas, nesse sentido, partem das relações e separações entre esfera pública e esfera privada e dizem respeito ao futuro dos direitos para as próximas gerações:

Pergunta 20. Qual a sua análise desses movimentos relativamente recentes? Há possibilidade desse "ideal de compliance internacional" fortalecer a noção de coletividade, de comunidade internacional em apoio ou substituição gradual dos constitucionalismos locais por um espírito público global cosmopolita que tenha como meta a realização dos direitos fundamentais constitucionais ou, ao contrário, esse mesmo ideal é um sintoma atual de nossos fracassos em afirmar a esfera pública localmente ou internacionalmente?

L.F.: Com uma fórmula sumária, direi que o garantismo, que é o conjunto de garantias adequadas para proteger e satisfazer os direitos fundamentais, exige, por um lado, um Estado penal mínimo (um “direito penal mínimo”, como tenho chamado o modelo garantista de direito penal) e, por outro lado, um Estado social máximo: em outras palavras, um passo atrás na esfera pública para tutelar as liberdades fundamentais e um passo à frente na garantia dos direitos sociais. O que é exatamente o oposto do que está acontecendo em nossas democracias, nas quais vieram à luz um direito penal máximo vinculado a demagogias populistas e um Estado social mínimo em conformidade com as instâncias do liberalismo. Em suma, oponho-me a todas as privatizações dos serviços públicos e de funções públicas de garantia, que sempre correm o risco de transformar em direitos patrimoniais aquilo que nossas Constituições configuraram como direitos sociais fundamentais. Uma característica distintiva dos direitos fundamentais é, de fato, a natureza gratuita de suas garantias - em particular dos benefícios devidos para o cumprimento dos direitos sociais - consequência de sua forma universal, como direitos de todos e fundamento da igualdade. E acho difícil imaginar uma escola particular gratuita ou um serviço de saúde privado gratuito.

Pergunta 21. A noção de governança é para alguns um fenômeno original do cálculo e da eficiência, manifestação atual e irrefreável do desenvolvimento mercantil moderno (Alain Supiot, La gouvernance par les nombres). Dela surgem consequências importantes, como a ideia de "jurimetria" ou o uso de quantificações estatísticas para refletir sobre a racionalidade do direito. Como exemplo positivo, podemos citar matéria atual nos jornais brasileiros dando a notícia de que, pela falta de critérios legais claros, a polícia decide quem é usuário e quem é traficante de drogas (https://noticias.uol.com.br/ultimas-noticias/agenciaestado/2019/03/31/sem-lei-que-cite-quantidades-policia-decide-quem-sera-preso-por-trafico. htm ). A informatização da vida e acesso amplo aos big data, o uso de estatísticas e métricas 
apresentam, todavia, outra face: o domínio da vida digital sobre as subjetividades, agora mediadas por "redes sociais digitais". Essa realidade infraestrutural afeta as profissões, sendo a manifestação mais clara nas profissões jurídicas a substituição de processos físicos por processos digitais, a virtualização de audiências via teleconferência e o acesso de supercomputadores como Watson (IBM) ou Coin (JP Morgan) a bases infindáveis de leis, regulamentos, contratos e acervos de jurisprudência. Em nome da já citada eficiência e governança, os poderes da justiça (Judiciário, Ministério Público, Defensorias, Advocacias) sentem seus efeitos: redução de pessoas e aumento de processos em quantidades sobrehumanas, que só podem ser geridos por grandes sistemas informáticos. Muitos profissionais no Brasil já se queixam da ausência de mediação humana na realização de direitos básicos dos cidadãos em suas relações com o Estado, entre eles o direito de ser ouvido, de ter suas petições lidas, além de outras garantias do devido processo legal.

Como o senhor vê esse conflito entre eficiência digital e garantismo no sentido humano, com processos que envolvem pessoas, manifestação das clássicas garantias do "juiz natural" ou "promotor natural" e outros direitos que compõem o acesso "real" e não "virtual" à justiça e ao Estado? A mesma era digital que permite enxergar distorções graves na desigualdade de tratamentos entre usuários de drogas revela uma tendência de alienar o juiz de seus réus, o Estado de seus cidadãos, as pessoas de seus representantes?

L.F.: Também "governança", parece-me, é um conceito ambíguo e fugidio, que não faz parte do léxico garantista. Quanto aos processos digitais, aos algoritmos e à substituição dos aparatos da esfera pública por aparelhos inteiramente informatizados, tudo isso me parece inquietante e, se não submetidos a limites e garantias, também perigosos. Esses algoritmos, esses automatismos com os quais estamos sob a ilusão de substituir a discricionariedade administrativa por uma espécie de eficiência objetiva e neutra escondem uma ameaça às garantias de direitos. $\mathrm{Na}$ verdade, eles não são neutros de modo algum. Eles são necessariamente construídos com base na escolha, nunca de forma avalorativa, de um ou mais parâmetros de avaliação maquiados como objetivos e na recusa ou irrelevância de outros critérios ou parâmetros. Eles, portanto, inevitavelmente produzem uma desresponsabilização e um ocultamento dos poderes por meio de seus procedimentos eficazes e de sua legitimação como poderes "técnicos".

Pergunta 22. O diagnóstico da crise política global está posto igualmente em sua obra mais recente, Manifesto per l'uguaglianza (2018). As tendências que o senhor narra ali ao analisar as relações entre direito e economia estão presentes em inúmeros países, especialmente os latinoamericanos submetidos à "nova ordem liberal". O senhor disse ali: "Essas políticas determinaram primeiro a crise e, em seguida, agravaram-na, propondo como terapias as mesmas medidas pelas quais a crise foi provocada: a desregulamentação 
das relações de mercado e, em particular, das atividades financeiras; a redução de impostos sobre os ricos, começando com os sobre a herança e, portanto, das receitas fiscais; a livre circulação de capitais, graças à qual estes podem escapar ao imposto, mudando-se para paraísos fiscais; os cortes nos gastos públicos em saúde e educação; a redução de salários e pensões; a precariedade do trabalho e a demolição do direito e dos direitos dos trabalhadores; a submissão às finanças, devido à qual os governos nos últimos anos alocaram centenas de bilhões de euros para salvar os bancos, depois de os terem privatizado e permitido que eles apostassem nos mercados, mas não conseguiram encontrar algumas dezenas de bilhões para salvar a Grécia do desastre econômico e social." (Ferrajoli, Luigi. "Manifesto per l'uguaglianza." Editori Laterza, 2018. iBooks, trad. livre). É no mesmo capítulo que o senhor faz uma crítica de passagem à concepção Law and Economics e cita o abandono de políticas keynesianas, dá como exemplo as políticas de intervenção feitas pelo governo Lula no Brasil e seu relativo sucesso na redução da miséria. $O$ senhor parece refletir um movimento presente por vezes tacitamente em todas as fundamentações de políticas públicas, no debate político e econômico que subjaz toda e qualquer fundamentação real de efetividade de direitos fundamentais, ambientais, sociais e humanos, ou de qualquer direito. É um movimento de fortalecimento da esfera pública, do Estado, para fazer frente ao privado, ao financeiro, à desregulamentação econômica.

Podemos dizer que essa doutrina é uma condição real e substantiva para as várias dimensões de constitucionalismos, do garantismo que o senhor defende há décadas? Podemos dizer que é um movimento de "Direito e Economia Política" para fazer frente à Law and Economics? Como o senhor poderia definir essa doutrina? Terão as gerações futuras condições de conquistar em âmbito internacional (ONU, FMI, OCDE, Banco Mundial etc.) um consenso de que não haverá direitos fundamentais sem políticas econômicas de Estado interventivas, de linha keynesiana, globalmente sustentáveis, mediante poderes públicos fortes, presentes e atuantes?

L.F.: A construção da esfera pública, repito, foi a grande conquista da modernidade jurídica e política. Naturalmente, a esfera pública também pode ser - foi e continua sendo em muitos países - uma esfera pública não-liberal ou antissocial e, portanto, antidemocrática. As constituições da segunda metade do século XX, apesar de suas limitações e defeitos, projetaram e impuseram a construção de uma esfera pública democrática, visando garantir as diversas classes de direitos fundamentais nelas estabelecidos. Hoje estamos testemunhando um ataque a essa esfera pública democrática, de cima a baixo. Na Itália, mas também em muitas outras democracias ocidentais, assistimos a uma aliança perversa e paradoxal entre o populismo e o liberalismo. As políticas liberais demoliram a legislação trabalhista e suas garantias e, consequentemente, as 
antigas formas de subjetividade coletiva baseadas na igualdade e nas lutas comuns pelos direitos comuns. Expressões como movimento operário e a classe operária saíram de uso porque, com a multiplicação, diferenciação e precarização das relações de trabalho, a igualdade de direitos entre os trabalhadores tem sido descumprida, porque em vez de se solidarizarem em lutas comuns, eles são forçados a competirem uns com os outros. Assim se criaram as bases sociais dos populismos atuais, que, com suas políticas de segurança, alimentam o medo e o racismo como fatores de novas subjetividades políticas coletivas, baseadas na defesa de supostas identidades coletivas - "primeiro os italianos" e similares - e supostas identidades inimigas e na intolerância às diferenças. Por sua vez, os populismos retribuem o favor que lhes foi dado por essa desintegração liberalista das antigas subjetividades sociais fazendo oposição, em nome de uma ilusória soberania nacional, à construção de uma esfera pública supranacional, de nível global ou ao menos europeu: exatamente a ausência de regras e controles à altura dos mercados, absolutamente funcionais para as políticas liberalistas. Finalmente, o populismo soberano e o liberalismo estão unidos pela intolerância a limites e obrigações constitucionais, gerada de um lado pela ideologia populista da vontade popular incorporada pela maioria como única fonte de legitimidade política e, de outro, pela ideologia liberalista do mercado como lugar de liberdades fundamentais que não admitem limites nem

controles. É, portanto, evidente que das duas soberanias, a popular e a dos mercados, a segunda está destinada a prevalecer sobre a primeira, nomeadamente por causa da assimetria entre o caráter global da economia e das finanças e o caráter predominantemente estatal da política e do direito. Direitos humanos, solidariedade e dignidade da pessoa - grande parte do vocabulário constitucional - são de resto ignorados tanto pela linguagem liberalista como pela linguagem populista.

\section{LUIGI FERRAJOLI - ENTREVISTA $3^{\text {a }}$ PARTE ENSINAR A CIDADANIA}

\section{Perguntas de GUILHERME MADEIRA DEZEM.}

Mestre e doutor em Direito Processual Penal pela USP. Professor de direito processual penal na Universidade Presbiteriana Mackenzie. Juiz de Direito em São Paulo.

Pergunta 23. Caro professor, o Brasil passa por momentos delicados: os valores democráticos e a proteção aos direitos humanos não encontram aderência junto à população em geral nem junto aos alunos de direito. Onde nós professores de direito erramos se não conseguimos passar esses valores aos alunos? O que podemos fazer?

Luigi Ferrajoli (L.F.): Vocês podem fazer muito. Primeiramente, mostrando o papel que a ciência jurídica, cujas disciplinas individuais geralmente parecem puramente técnicas 
e certamente não empolgantes, pode desempenhar na crítica ao direito ilegítimo, isto é, ao exercício ilegítimo dos poderes, tanto públicos quanto privados. Nisso consiste o maior fascínio da ciência jurídica tal como foi refundada pelas constituições rígidas de hoje e que o ensino tem a tarefa de revelar. O direito pode ser um poderoso instrumento para a construção da democracia, tanto quanto é capaz de operar como um sistema de limites e obrigações para os poderes, que de outra forma seriam selvagens, e de garantir os direitos fundamentais a todos. Infelizmente, não é só o Brasil que passa por uma crise da democracia. Também a Itália, grande parte da Europa, até os Estados Unidos estão vivendo crise semelhante. É importante mostrar aos alunos que, nessas crises involutivas não há nada de natural ou inevitável; que os sistemas políticos são como os construímos no plano jurídico, como os imaginamos e os queremos politicamente e, antes de tudo, como os pensamos em um nível teórico. Por essa razão, eles dependem - e exigem - a responsabilidade de todos nós, começando por nós juristas.

Pergunta 24. Percebemos que no mundo há uma onda que repele os direitos e garantias, notadamente aqueles conhecidos como de primeira geração ou dimensão. Viktor Orban, Matteo Salvini, Donald Trump e, no Brasil, Jair Bolsonaro são a face visível deste movimento. Aparentemente, trata-se de um movimento pendular. Quanto tempo podemos esperar de duração desse movimento? Qual a melhor postura que nós professores devemos ter?

L.F.: São movimentos que crescem sobretudo no vazio de cultura política e jurídica: um vazio que facilmente acaba sendo preenchido com medo, xenofobia, ressentimentos, recriminações, egoísmos individuais e nacionais alimentados por demagogias irresponsáveis e muitas vezes por falsificações e mistificações da realidade. A melhor resposta, repito, é o desenvolvimento do senso cívico, da cultura jurídica e política e também a invenção de novas técnicas ou formas de garantia capazes de reduzir os poderes que, de outro modo seriam, como sempre, selvagens e destrutivos.

\section{Pergunta de DANIEL GUIMARÃES ZVEIBIL.}

Doutor e mestre em direito processual pela USP, em temas de direito processual constitucional. Cursa segundo ano de Fundamentos da Psicanálise e sua Prática Clínica no Instituto Sedes Sapientiae. Professor de Direito Processual. Membro do CEAPRO (Centro de Estudos Avançados de Processo) e do IBDP (Instituto Brasileiro de Direito Processual). Defensor Público do Estado de São Paulo com atribuições no I Tribunal do Júri da capital.

Preâmbulo: Se considerarmos a perspectiva da segunda acepção de "garantismo", muitas das práticas operadas pela Justiça Penal brasileira são incompatíveis ao modelo de garantias vigentes e também decisivas para o processo de aprisionamento em massa que está em curso, posicionando o Brasil entre os líderes mundiais nessa matéria. O quadro é muito preocupante, e o excesso de prisões provisórias revelam que os tribunais encaram a maior parte dos réus como presumidamente culpados, nascendo dessa visão distorcida outros inúmeros desajustes das práticas operadas em 
relação, ao próprio Código de Processo Penal (na parte em que houve alterações importantes realizadas por reforma de cunho predominantemente garantista em 2008, que em vários aspectos foi simplesmente ignorada pela jurisprudência) e ao modelo constitucional estipulado pela Constituição brasileira e pelos tratados e jurisprudência internacional de direitos humanos que vinculam o Brasil. Mesmo com novas gerações de estudantes de direito formadas em contato com o pensamento garantista, não se entreabre alguma percepção de significativo arrefecimento das práticas antigarantistas do sistema de Justiça. Esta falta de mudança significativa aponta, entre outros fatores, o efeito alienante obtido em longos processos de institucionalização a que os novatos são submetidos nas carreiras do sistema de Justiça (o que inclui cursos de formação, normas correcionais, metas de produtividade etc), confirmando neles o padrão geral de normalidade imposto ou, se o caso, adequando-os a esse padrão (de práticas antigarantistas consolidadas pela jurisprudência brasileira). Essa percepção converge assustadoramente à compreensão de Albert Schweitzer, em seu estudo Decadência e Regeneração da Cultura (Verfall und Wiederaufbau der Kultur), ao advertir que "um outro motivo pelo qual a renovação da cultura é dificultada consiste em que, na qualidade de realizadores do movimento, e de maneira decisiva, só podem ser tomadas em consideração individualidades isoladamente. A regeneração da cultura nada tem a ver com movimentos relacionados à psicologia das multidões. (...) Ali onde as coletividades exercem mais influência sobre o indivíduo do que este possa exercer sobre elas, começa irremissivelmente a decadência (...)". Por outro lado, no prefácio de Direito e Razão: Teoria do Garantismo Penal, Norberto Bobbio acentua que o mais perfeito sistema do garantismo não pode encontrar em si mesmo sua própria garantia e exige a intervenção ativa por parte dos indivíduos e dos grupos na defesa de direitos que, mesmo normativamente declarados (positivados), nem sempre estão efetivamente protegidos.

Pergunta 25. Diante dessa perspectiva, o que o senhor aconselharia no campo do ensino jurídico para que nós, professores de direito, formemos indivíduos realmente convencidos da necessidade de se lutar pelos direitos decorrentes do modelo vigente de garantias, e a ponto de terem força interior suficiente para rejeitarem qualquer tentativa de normalização institucional de práticas antigarantistas?

L.F.: A educação jurídica é hoje, principalmente, a educação para valores constitucionais, isto é, para os valores da liberdade, igualdade, da paz e da democracia. A educação civil para esses valores e suas garantias e o desenvolvimento do compromisso político e intelectual, especialmente dos jovens, será tanto mais eficaz quanto mais eles conseguirem promover a indignação contra o arbítrio e o abuso: a indignação, por exemplo, contra a presunção de culpa que, como você diz, parece animar os tribunais brasileiros, e contra o consequente abuso da prisão cautelar, das prisões em flagrante e das conduções coercitivas, que são os tantos sintomas 
da escassa cultura institucional de nossos operadores jurídicos. Você lembra com razão o que Norberto Bobbio escreveu sobre a intervenção ativa das pessoas na defesa dos direitos. Somente a luta diária e radical em defesa dos direitos pode garantir sua eficácia. Na ausência dessa luta, os direitos estão destinados a desaparecer do horizonte da política e até mesmo antes que os próprios cidadãos, seus titulares.

Além disso, o ensino deve mostrar que os valores constitucionais não são apenas valores éticos e políticos. Eles são, em primeiro lugar, valores da razão. De suas lesões podem surgir catástrofes que podem destruir não só as nossas democracias, mas também as nossas condições de vida e sobrevivência. Este é um novo perigo na história da humanidade: em face de catástrofes ambientais ou nucleares, se limites e controles não forem introduzidos - em resumo, garantias - capazes de pôr fim ao atual desenvolvimento industrial ecologicamente insustentável e banir como ilícitas as absurdas armas nucleares, poderíamos não mais chegar a tempo de formular os "nunca mais" que, em meados do século passado, confrontaram os horrores das guerras e os totalitarismos. A luta por direitos e por suas garantias é, em suma, um imperativo da razão antes mesmo que da justiça. É um todo com esforço racional, e não apenas ético-político, em defesa da democracia, da paz e da habitabilidade do planeta. 